Revista de
Economì
Contemporâned

\title{
EMISSÃO DE TíTULOS DA DÍVIDA PÚBLICA BRASILEIRA EM REAIS NO EXTERIOR: CONTEXTO E CARACTERÍSTICAS
}

\begin{abstract}
Roberto Meurer ${ }^{\text {a }}$

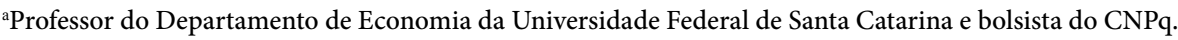

Artigo recebido em 01/04/2013 e aceito para publicação em 22/09/2014.

RESUMO: A estabilidade macroeconômica e a menor vulnerabilidade externa possibilitaram a emissão de títulos da dívida pública externa brasileira denominados em reais, a partir de 2005. A importância dessas emissões está em criar uma referência para a emissão de títulos corporativos, porque os títulos soberanos refletem o risco sistemático associado à economia do país. Uma vantagem da emissão em reais no exterior é a ausência do risco de câmbio para o devedor doméstico, o que também pode ser utilizado como operação de hedge por parte de investidores externos, e não estão sujeitos ao risco de conversibilidade. As emissões brasileiras ocorreram com prazos mais longos que o dostítulos comparáveis emitidos no mercado doméstico. $\mathrm{O}$ fato de o país não depender dos recursos das captações externas para fazer frente ao serviço de sua dívida permitiu a escolha dos momentos favoráveis à emissão em termos de custos.
\end{abstract}

CLASSIFICAÇÃO JEL: F34; F32; H6.

PALAVRAS-CHAVE: Dívida externa; emissão em reais; títulos soberanos; Brasil.

Correspondência para Roberto Meurer.

Email: roberto.meurer@ufsc.br. 


\section{CONTEXT AND FEATURES OF BRAZILIAN PUBLIC DEBT ISSUES DENOMINATED IN REAIS ABROAD}

ABSTRACT: Macroeconomic stability and lower external vulnerability have allowed the issuance of Brazilian external debt bonds denominated in Brazilian reais since 2005. Those issuances have not been used to finance current account deficits. They are important to build a benchmark for corporate bond issuances, associated with the systemic risk of the Brazilian economy. Bond emissions in local currency usually have the advantage of eliminating the exchange rate risk for the debtor. It might also be used as hedge for an external investor, and they are not exposed to the convertibility risk, related to foreign reserve shortages or capital controls. Brazilian issuances of securities abroad denominated in local currency have had longer maturity than comparable bonds in the domestic market in the period. Since the country does not depend on foreign issuances to pay its debt, the monetary authority has been able to choose more favorable moments for the issuances in terms of the returns paid on the bonds.

KEYWORDS: External debt; bonds issued in Brazilian reais; sovereign debt; Brazil.

\section{INTRODUÇÃO}

Os investimentos externos, diretos ou de carteira, são tradicionalmente utilizados por economias em desenvolvimento ou emergentes para financiar os seus déficits em transações correntes. A partir da década de 1990, com a liberalização financeira, o endividamento tradicional, por meio de contratos de dívida, foi em grande parte substituído por emissão de títulos. Na estratégia de utilização de financiamento externo, a experiência mostra que a abertura financeira deveria ocorrer após a abertura comercial (Edwards, 2008), por causa da influência da abertura sobre o crescimento econômico e a maior exposição ao mercado financeiro internacional. Por outro lado, as reformas que levam à redução dos déficits fiscal e externo, e a adoção do câmbio flexível reduzem a probabilidade de crises de balanço de pagamentos (Edwards, 2008). A estabilidade macroeconômica, portanto, desempenha importante papel na atração de financiamento externo.

Em períodos recentes ocorreu uma rápida expansão dos volumes de investimento externo em carteira (IEC), com o estoque de títulos emitidos em mercados internacionais ultrapassando 29 trilhões de dólares em 2011 (BIS, 2011). A participação do Brasil no estoque global de títulos de dívida era de $0,7 \%$, em setembro de 2011 , correspondendo a 202 bilhões de dólares (BIS, 2011). No estoque da dívida externa brasileira registrada o volume denominado em moeda brasileira era de 12,5 bilhões de dólares em setembro de 2011, o que corresponde a uma participação de $4,8 \%$ do total de 261,5 bilhões de dólares. Apesar de este volume parecer pequeno em termos absolutos e relativos, é interessante observar que é crescente, especialmente a partir de 2005. A dívida externa total brasileira, não incluindo os empréstimos intercompanhias, era de 298,2 bilhões de dólares em dezembro de 2011.

O volume de títulos emitidos pelo governo brasileiro em reais no exterior já influencia a composição da dívida pública externa brasileira e o seu custo. A emissão de títulos em reais no exterior pelo governo brasileiro, procurando criar um benchmark para títulos privados, pode significar uma alternativa adicional de diversificação de risco ou hedging para o setor privado, com efeitos sobre o custo de capital para as empresas nacionais. Com isto, é possível que a emissão de títulos públicos não tenha seu efeito restrito ao custo do endividamento do governo, mas afete também o custo e o risco da emissão de títulos para o restante da economia, o que torna relevante a análise dos efeitos do cenário macroeconômico nacional e internacional sobre as condições de emissão dos títulos brasileiros.

O objetivo deste artigo é verificar como o cenário macroeconômico nacional e internacional afetam as condições para a emissão de títulos públicos brasileiros denominados em reais no exterior e sua relação com a evolução de indicadores domésticos 
da dívida pública, porque existem títulos similares sendo negociados nos mercados interno e externo.

O artigo está estruturado em cinco seções, incluindo esta introdução. Na seção 2 são discutidas as motivações que levam à emissão de títulos denominados em moeda local no exterior. A seção 3 analisa os dados de composição da dívida externa brasileira em termos de sua moeda de denominação, características das emissões em moeda local, conjuntura associada às emissões e possíveis relações com a dívida mobiliária interna. Na seção 4 são discutidas as implicações das emissões para a política econômica e o mercado financeiro local. As principais conclusões são apresentadas na seção 5 .

Conclui-se que as emissões em reais não são utilizadas para o financiamento de déficits em transações correntes, mas sim para a criação de benchmark para as emissões corporativas e obtenção de informações a respeito da percepção sobre a economia do país. Por isso, há flexibilidade para a escolha dos momentos em que os títulos são emitidos. As emissões externas em reais têm prazos mais longos que os títulos nacionais similares, o que pode gerar efeitos das emissões externas sobre o mercado interno.

\section{MOTIVAÇÕES PARA DÍVIDA EXTERNA E DÍVIDA EXTERNA EM MOEDA LOCA}

Ao conceder empréstimo ou financiamento tradicional ou adquirir títulos, o fornecedor de recursos estará fazendo um cálculo de rentabilidade esperada sobre o investimento e o risco envolvido, que não são exatos por causa de alterações no cenário econômico do país tomador e da economia mundial. Na literatura de finanças isto corresponde ao risco sistêmico e específico ou idiossincrático para a economia mundial e do país, respectivamente. O risco específico será diferente para cada país e em cada país, diferente para diferentes ativos financeiros e ativos reais. Isto significa a necessidade de considerar o risco país e o risco associado ao ciclo econômico e as oscilações no mercado financeiro internacional.

Tanto para o tomador de recursos quanto para o fornecedor, a moeda em que o título é denominado leva à existência de um risco cambial, se emitido em moeda diferente da do país de origem do emissor ou adquirente do título. O diferencial de juros e as expectativas de variação cambial compõem a rentabilidade esperada do título e explicam, em conjunto com as diferenças de percepção de risco, a ocorrência de taxas de retorno diferentes em diferentes moedas para títulos com as mesmas características e o mesmo emissor. Para os emissores domésticos a emissão de títulos no exterior denominados em moeda nacional evita o risco cambial associado a essas operações.

Dados os juros internos, a existência de um mercado externo de títulos na mesma moeda pode gerar oportunidades de arbitragem que, quando exploradas, tendem a levar à sua eliminação. Caso o mercado externo seja mais eficiente que o interno, a possibilidade de substituição do local de emissão do título pode ser um fator de pressão para o aumento da eficiência do mercado financeiro doméstico, com efeitos similares ao da liberalização do mercado financeiro nacional (Errunza, 2001; Bekaert e Harvey, 2000).

Nos últimos anos, especialmente, a partir de 2003, o diferencial entre juros externos e internos aliado à tendência de apreciação da moeda brasileira gerou uma elevada rentabilidade dos ativos de renda fixa denominados em moeda brasileira, em comparação ao retorno de ativos denominados em moedas dos países desenvolvidos. O efeito macroeconômico do diferencial de juros, por meio da apreciação da moeda brasileira, foi a redução da competitividade da produção local em relação à internacional. No caso do setor público, a emissão de títulos externos sem a necessidade de conversão das divisas em moeda local poderia reduzir a pressão sobre a taxa de câmbio e a consequente necessidade de esterilização dessas operações. Para emissões do setor privado, entretanto, não é óbvia a possibilidade de a pressão cambial poder ser reduzida com a emissão de títulos em moeda doméstica no exterior. Mesmo no caso do governo, a ausência do risco cambial para a dívida externa com a emissão de títulos em moeda nacional não significa que o custo fiscal da dívida externa seja eliminado, por causa da menor remuneração das reservas internacionais em comparação ao custo da dívida, porque a percepção de risco dos títulos em moeda local e a taxa de juros real são elevadas.

A emissão de títulos brasileiros no exterior denominados em reais pode ter impacto no custo e risco da dívida pública. A composição da dívida pública externa é sujeita a decisões de otimização intertemporal relacionadas com o custo da dívida, a probabilidade de default e o custo do default, o que pode significar que a minimização do custo da dívida não seja a melhor alternativa (Dooley, 2000), o que é condizente com o fato de vários países terem uma gestão subótima da dívida do ponto de vista de seu custo (Hussein e Mello Jr., 2001). Do ponto de vista do governo emissor, em um país cuja arrecadação tributária não seja predominantemente gerada por operações do setor externo, a emissão de dívida externa em moeda local pode significar uma redução da exposição a variações da taxa de câmbio, aproximando o país da situação de países desenvolvidos que não têm dificuldade em emitir títulos denominados em suas moedas.

O objetivo explícito do governo brasileiro - ao lançar títulos em moeda brasileira no mercado externo - é criar uma curva de juros longa que sirva de parâmetro para as emissões privadas. Estas emissões podem afetar também o mercado de títulos nacional. Ocorre reação do mercado de títulos emitidos por empresas em reais no exterior às emissões soberanas, mas esta reação não é uniforme ao longo do tempo (Salgado, 
2009), o que torna interessante analisar os fatores que afetam as emissões de títulos públicos. O momento em que estes títulos são lançados refletirá as expectativas sobre o comportamento da economia do país, incluindo inflação, política monetária, câmbio e crescimento econômico.

O cenário macroeconômico e a percepção de risco afetam as condições em que são emitidos os títulos públicos brasileiros em moeda brasileira no exterior. Caso o mercado financeiro internacional esteja sujeito à ocorrência de sobre-reação a notícias recentes (De Bondt e Thaler, 1990) ou ocorram descolamentos dos preços dos ativos financeiros em relação a seu valor fundamental é possível que existam momentos em que o lançamento de títulos seja mais propício.

A relação entre as expectativas de mercado e os fundamentos macroeconômicos é evidente, porque a emissão de títulos prefixados em reais com vencimento em 2016, 2022 ou 2028, pressupõe que não haja uma percepção generalizada de ocorrência de hiperinflação ou crise do balanço de pagamentos nesse horizonte, e os títulos podem funcionar como sinalização desse compromisso nos mercados financeiros internacionais.

A maior integração da economia de um país aos mercados financeiros internacionais pode, por um lado, facilitar a obtenção de financiamento externo em período de disponibilidade de recursos, mas, por outro, torna o país mais exposto nos momentos de crise (Griffith-Jones e Ocampo, 2009). O fluxo de pagamentos ao detentor do ativo, por outro lado, depende da geração de renda por esse ativo. Mesmo que o preço dos ativos se descole dos fundamentos do rendimento gerado pela sua utilização, ao longo do tempo deverá ocorrer a compatibilização entre o fluxo de rendimentos e o preço, por meio da arbitragem entre ativos, substitutos entre si em maior ou menor grau.

Com base na teoria de finanças, a diversificação de composição da dívida em termos de moeda de denominação pode levar à redução do risco, dependendo das variâncias das taxas de câmbio e suas correlações. A emissão de títulos em diferentes moedas insere-se no contexto mais amplo dos pull e push factors (Hoti, 2004). Isto significa que variáveis macroeconômicas nacionais e internacionais poderão influenciar a composição da dívida em termos de moeda de denominação.

A composição ótima da dívida externa em termos de taxa de câmbio está relacionada com a volatilidade de juros, câmbio e preços das commodities, com efeito nas contas externas do país (Claessens, 1992). Esta é uma questão que atinge, principalmente, países em desenvolvimento. A capacidade de emissão de títulos em moeda local pode significar uma mudança de patamar de inserção do Brasil no mercado financeiro internacional, refletindo-se em modificações de risco e retorno desses títulos.

O subdesenvolvimento do mercado de títulos é um dos motivos para o fraco desempenho dos mecanismos de transmissão da política monetária. Uma das explica- ções para isso é o benefício fiscal da inflação (Jeanneau e Tovar, 2008). Inflação elevada, por outro lado, impede a emissão de títulos prefixados longos, por causa da inflação elevada e variável (Burger e Warnock, 2003). Por isto, um mercado externo de títulos em moeda local solidamente estabelecido pode gerar um incentivo para a melhoria dos mercados nacionais de títulos. A importância do desenvolvimento do mercado de títulos é discutida em Fabella e Madhur (2003).

Uma das principais vantagens da colocação de títulos soberanos no mercado internacional é a criação de um benchmark para colocações privadas (Yuan, 2005). Os títulos soberanos representariam o risco sistemático da economia, refletindo o estado e as expectativas da economia em sentido macro, importante para a definição do custo de emissões específicas de empresas, que representaria um risco corporativo específico ou idiossincrático. Dittmar e Yuan (2008) testam a hipótese de que os títulos soberanos funcionam como um benchmark para emissões corporativas e concluem que as emissões soberanas têm efeitos de redução de rendimentos e aumentos de liquidez para os títulos corporativos. Salgado (2009) testa essa hipótese para o caso brasileiro e comprova a influência das emissões soberanas sobre as emissões corporativas. O efeito sobre o rendimento e o bid-ask spread são contraditórios para a amostra estudada.

Uma questão envolvendo a emissão de títulos em reais no exterior é a possibilidade de migração dos negócios com esses títulos para o exterior, reduzindo os volumes nos mercados nacionais. Este seria um processo análogo à discutida migração dos negócios com ações brasileiras para o mercado de ADRs nos Estados Unidos. Por outro lado, a ampliação da base de potenciais adquirentes dos títulospoderia levar a uma redução dos custos, um benefício equivalente ao da liberalização da conta financeira do balanço de pagamentos (Clark e Berko, 1997).

Os riscos na aquisição de títulos soberanos no país emissor desses títulos são o risco cambial, quando denominados em moeda local, e o risco de conversibilidade. $\mathrm{O}$ primeiro decorre da oscilação da cotação da moeda do país emissor em relação à moeda do país do investidor. O risco de conversibilidade vem da possibilidade de o país não dispor de recursos em moeda conversível para honrar os pagamentos quando devidos ou ocorrerem controles de capitais. As emissões soberanas no exterior na moeda local eliminam o risco de conversibilidade, mas mantém o risco cambial, o que pode ser interessante para as operações especulativas envolvendo a direção da taxa de câmbio ou para operações de hedge associadas a posições na moeda local.

Teoricamente, pela paridade internacional de juros, o custo da emissão soberana em moeda nacional será dado pelo juro externo acrescido da expectativa de variação cambial e um prêmio pelo risco. Em comparação com o título emitido no mercado doméstico, como o título emitido no exterior não tem o risco de conversibilidade, 
existe a possibilidade de o custo da emissão externa ser inferior à emissão doméstica. Este resultado foi encontrado para emissões colombianas em Jeanneau e Tovar (2008).

A emissão de títulos prefixados pressupõe algum grau de previsibilidade do valor da moeda em que o título é denominado ao longo do tempo até o seu vencimento. Isto significa que não podem estar no horizonte eventos extremos como uma hiperinflação. Isto se aplica tanto ao caso do título emitido no mercado interno quanto no caso do emitido no mercado externo, em que o valor a ser recebido também será influenciado pela taxa de câmbio. Isto decorre do risco de o mercado de títulos emitidos nos mercados interno e externo tender a convergir, diferindo, entretanto, no risco de conversibilidade.

Os compradores dos títulos, portanto, avaliarão o retorno esperado, que incorporarão as expectativas das variáveis que influenciam esses retornos. Isto dá relevância ao comportamento prospectivo das variáveis macroeconômicas, especialmente, a inflação e a taxa de câmbio que, por sua vez, estão ligadas a um amplo conjunto de variáveis monetárias e fiscais, além de aspectos estruturais da economia doméstica e internacional.

O fato de o retorno ex post do título estar relacionado com a inflação torna importante a sua previsibilidade e variabilidade. Como é amplamente discutido na teoria de estrutura a termo da taxa de juros, o prêmio pelo risco aumenta com o prazo do título, por causa das perdas que podem ocorrer caso o juro ao longo da vida do título aumente em relação ao previsto no momento da aquisição. O prêmio acima da expectativa dos juros de curto prazo ao longo da vigência do título deverá, portanto, refletir a própria previsibilidade e variabilidade dos juros e, em última instância, a estabilidade e expectativas em relação à economia do país. A política econômica e sua credibilidade, portanto, têm efeito direto sobre a capacidade de o país emitir títulos denominados em sua moeda no exterior.

\section{DADOS E ANÁLISE}

\subsection{INSERÇÃO EXTERNA E COMPOSIÇÃO DA DÍVIDA EXTERNA}

O Gráfico 1 mostra a evolução do estoque de títulos de dívida em circulação em escala global. As mudanças estruturais no sistema financeiro mundial, no contexto de maior desintermediação dos mercados, explica o rápido crescimento, em termos reais, do volume de títulos em circulação. Mesmo a crise financeira generalizada de 2008 interrompeu apenas, brevemente, a tendência de crescimento do volume de títulos de dívida no mercado. É interessante observar, por outro lado, que a maior volatilidade observada no mercado desses títulos em período recente gerou maior variabilidade também no seu estoque, dadas as situações de impossibilidade de emitir títulos por falta de demanda ou aos custos muito elevados que inibem a oferta por parte dos demandantes de recursos. O volume total, de 29,8 trilhões de dólares em setembro de 2011, precisou de pouco mais de sete anos para alcançar mais do dobro dos 14,8 trilhões de dólares existentes em junho de 2004. Com relação ao início da década de 1990, quando o mercado financeiro internacional iniciou a sua normalização após a crise das dívidas externas da década de 1980, o volume mais que decuplicou. A taxa de crescimento geométrica entre o final de 1990 e setembro de 2011 é de 11,9\% ao ano consideravelmente superior às taxas de crescimento do PIB mundial no mesmo período, cuja média foi de $2,2 \%$ ao ano.

\section{Gráfico 1 - Estoque global de títulos de dívida (em US\$ bilhões de setembro de 2011)}

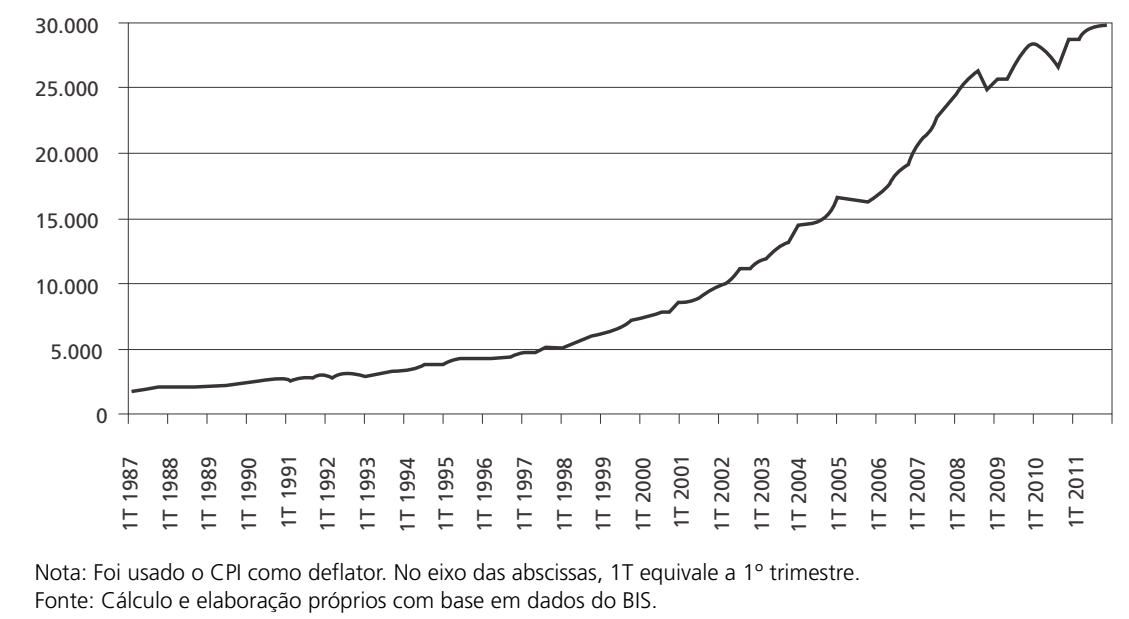

A evolução da participação brasileira no estoque global de títulos de dívida é mostrada no Gráfico 2. A inserção do Brasil nesse mercado é afetada pelo desenrolar da crise da dívida externa, que estourou em 1982. O Brasil decretou a moratória dessa dívida em 1987,quando já estava inadimplente há vários anos. O longo processo de renegociação da dívida externa brasileira, desde o primeiro recurso ao FMI em 1982, somente foi concluído em 1994, quando a quase totalidade da dívida foi substituída por títulos, os Brady bonds, emitidos no âmbito do plano Brady. Esta emissão de títulos em substituição às dívidas vencidas explica o salto da participação do Brasil no estoque de títulos em circulação, de $0,52 \%$ para $2,3 \%$ entre março e junho de 1994 . A partir de 1995 o Brasil novamente tem acesso aos mercados financeiros internacionais. 
Uma completa descrição do processo de negociação da dívida externa brasileira nas décadas de 1980 e 1990 e da reinserção do país no mercado financeiro internacional pode ser encontrada em Cerqueira (2003).

Após se manter estável por algum tempo, a partir do segundo semestre de 1998, a participação do Brasil no estoque mundial de títulos cai. Este movimento relaciona-se, em um primeiro momento, com a dificuldade de acessar o mercado externo por parte do governo e empresas brasileiras. O Brasil tinha um elevado déficit em transações correntes, gerado pela apreciação da moeda brasileira em um regime de câmbio semi-fixo. A percepção de insustentabilidade do regime cambial, dependente da captação de recursos externos, praticamente inviabilizou a emissão de títulos no exterior. A mudança para um regime de câmbio flutuante no início de 1999 permitiu iniciar o processo de reversão do déficit em transações correntes, em que foram gerados superávits a partir de 2003 até 2007. O mercado externo dificultou novamente as emissões brasileiras com a crise argentina em 2001 e a crise eleitoral de 2002.

\section{Gráfico 2 - Participação do Brasil no estoque mundial de títulos de dívida (em \%)}
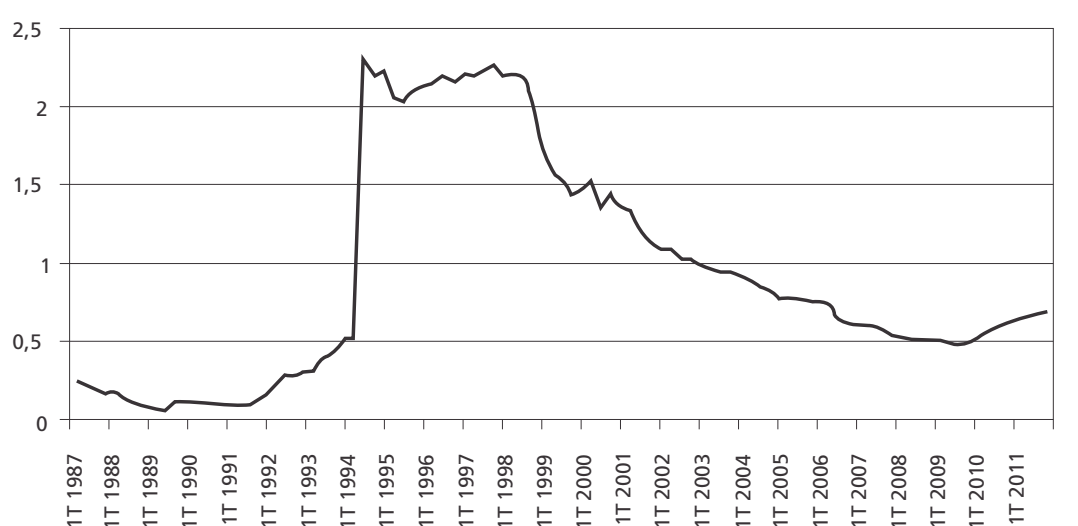

ota: No eixo das abscissas, $1 T$ equivale a $1^{\circ}$ trimestre.

Fonte: Cálculo e elaboraçăao próprios com base em dados do BIS.

A partir de 2003 o governo brasileiro adotou uma política explícita de reduzir o passivo em moeda estrangeira, tanto para a dívida interna quanto para a externa. Isto foi possível pela geração de superávits em transações correntes e entrada de investimento estrangeiro direto. A estabilidade macroeconômica e as taxas de juros elevadas tornaram as emissões brasileiras atraentes para compradores de títulos no mercado internacional. Isto permitiu, por exemplo, a gradativa troca de títulos emitidos através do plano Brady por títulos emitidos em mercado, o que marca a normalização da inserção brasileira no mercado financeiro internacional.
A composição da dívida externa de acordo com a sua moeda de denominação sofreu algumas modificações importantes nos anos recentes, como pode ser observado na Tabela 1. Em momento algum o dólar perdeu a sua predominância, tendo aumentado a sua participação. A participação do dólar na dívida em setembro de 2011 é a segunda maior da série histórica iniciada em 1977, inferior somente à de dezembro de 1997. O euro perde participação ao longo do tempo, o que também acontece com o iene, embora este tenha apresentado um pico de participação em 2007 e 2008. A participação dos Direitos Especiais de Saque (DES) é praticamente eliminada quando o governo brasileiro quita a dívida externa com organismos multilaterais e substitui a dívida renegociada por títulos emitidos nos mercados.

A participação do real na dívida externa brasileira passa a ser relevante quando o governo brasileiro passa a emitir títulos denominados em real. É interessante observar que a participação do real na dívida não aumenta continuamente. A crise internacional de 2008 levou a uma interrupção da emissão, primeiramente por retração da demanda e, em 2009 e na maior parte de 2010, por não serem efetuadas ofertas em um cenário externo desfavorável em termos de custos para eventuais emissões brasileiras.

Tabela 1 - Participação das moedas na dívida externa registrada do Brasil (em \%)

\begin{tabular}{lcccccccccc}
\hline & USD & JPY & CHF & GBP & CAD & DES & EUR & BRL & OUTRAS & TOTAL \\
\hline Dez/2004 & 69,52 & 6,49 & 0,20 & 0,35 & 0,07 & 13,49 & 9,40 & 0,1 & 0,36 & 100,00 \\
Dez/2005 & 82,10 & 6,82 & 0,09 & 0,33 & 0,08 & 0,01 & 8,23 & 2,04 & 0,31 & 100,00 \\
Dez/2006 & 81,42 & 7,10 & 0,05 & 0,19 & 0,04 & 0,01 & 7,23 & 3,70 & 0,26 & 100,00 \\
Dez/2007 & 74,72 & 10,89 & 0,03 & 0,07 & 0,04 & 0,01 & 6,19 & 7,89 & 0,17 & 100,00 \\
Dez/2008 & 79,05 & 9,36 & 0,04 & 0,08 & 0,00 & 0,00 & 5,26 & 5,26 & 0,93 & 100,00 \\
Dez/2009 & 79,93 & 6,24 & 0,05 & 0,07 & 0,00 & 2,56 & 4,90 & 6,1 & 0,13 & 100,00 \\
Dez/2010 & 82,80 & 4,53 & 0,16 & 0,07 & 0,00 & 1,98 & 4,95 & 5,5 & 0,00 & 100,00 \\
Set/2011 & 85,56 & 3,09 & 0,23 & 0,08 & 0,00 & 1,73 & 4,53 & 4,78 & 0,00 & 100,00
\end{tabular}

Fonte: Banco Central do Brasil.

A emissão de títulos da dívida pública externa brasileira em reais, a partir de 2005, ocorre quando as contas externas do país melhoram em comparação com as décadas anteriores. A geração de superávits em transações correntes na primeira metade da década de 2000, a mudança no perfil da dívida externa e a acumulação de reservas internacionais reduzem, consideravelmente, a vulnerabilidade externa da economia brasileira. Isto também influencia a composição da dívida externa entre pública e privada. 
Como pode ser observado no Gráfico 3, existe uma certa substituição no volume total de dívida externa entre pública e privada. A dívida privada aumenta fortemente entre 1995 e 1998 e cai entre 1999 e 2005. Este foi um período conturbado da inserção brasileira no mercado financeiro internacional, influenciado por crises em países emergentes, como as dos países asiáticos, a russa e mesmo a brasileira. Esta levou à adoção do câmbio flutuante em 1999. A crise cambial gerada pela eleição de 2002 ensejou a continuidade desse processo. Nesses períodos de retração do setor privado tende a ocorrer uma elevação da dívida do setor público. Em períodos de cenário externo favorável, como a partir de 2009, após a crise financeira internacional, a elevação da dívida privada é mais acelerada. A já comentada melhoria da situação das contas externas brasileiras, a partir de 2003, possibilitou maior flexibilidade para o governo brasileiro, que passa a escolher momentos favoráveis à captação externa. Isto é possível porque o governo não está pressionado pelos vencimentos de dívida a se sujeitar a quaisquer circunstâncias para captar recursos, por ter reservas internacionais que dão folga para administrar no tempo as emissões de dívida. Esta gestão inclui as emissões em reais, como será discutido posteriormente.

O Gráfico 3 também permite observar a redução acentuada da dívida externa total de 1999 a 2006 e o forte crescimento entre 2010 e 2011. Esta trajetória mostra uma inter-relação importante entre o cenário nacional, que influenciou a queda, com as condições do mercado internacional, em que a abundância de liquidez permitiu o aumento da oferta de recursos que possibilitou a expansão da dívida.

\section{Gráfico 3 - Dívida externa registrada do Brasi} (em US\$ bilhões de setembro de 2011)

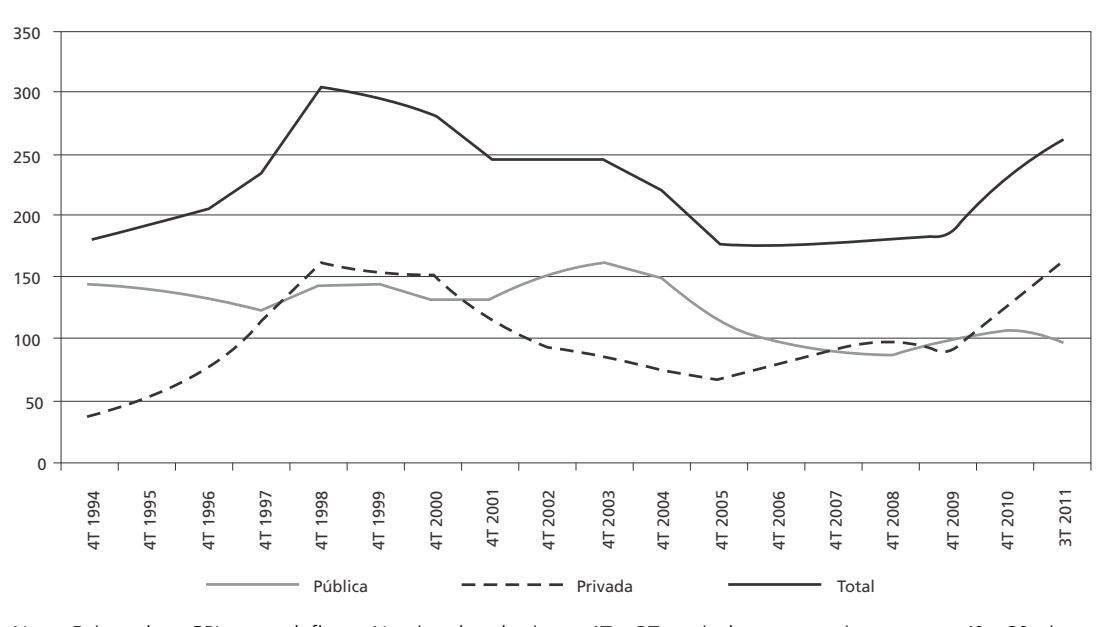

Nota: Foi usado o CPI como deflator No eixo das abscissas, $4 \mathrm{~T}$ e $3 \mathrm{~T}$ equivalem, respectivamente, a $4^{\circ} \mathrm{e} 3^{\circ}$ trimestres. Fonte: Cálculo e elaboração próprios com base em dados do Banco Central do Brasil.

\subsection{EMISSÕES BRASILEIRAS}

A Tabela 2 mostra as emissões de títulos soberanos pelo Brasil de 1995 a 2011. Há consideráveis diferenças nos volumes emitidos ao longo do tempo, tanto nas emissões totais quando nas em reais. A situação do mercado financeiro internacional e das contas externas do país determinam essas oscilações. O elevado volume de emissões em 1999, 2000 e 2001 decorre da necessidade de fazer frente ao serviço da dívida externa, em um momento em que o setor privado reduz o seu endividamento por causa dos elevados custos. Em 2005 a elevada liquidez externa permitiu a rolagem dos títulos vincendos e a troca de títulos da dívida renegociada (C-bonds e A-bonds) por títulos emitidos em mercado. O superávit em transações correntes, a entrada de investimento externo direto e as colocações de títulos permitem aumentar as reservas internacionais. Esta redução da vulnerabilidade externa juntamente com a continuidade da política econômica interna de controle da inflação e ajuste das contas públicas possibilita a primeira emissão em reais. O objetivo explícito é reduzir a exposição do país a fatores externos (Banco Central do Brasil, 2005).

A preocupação com o custo da emissão de títulos da dívida externa estende-se às emissões em reais. Isto é evidenciado pela ausência de emissões em 2008, 2009 e 2011. Especialmente em 2008 e 2009 o cenário externo e seus reflexos sobre a economia brasileira, incluindo crescimento e juros, desincentivaram as emissões. A emissão de 2010 foi de valor baixo. A piora do cenário externo no segundo semestre de 2011 torna menos atrativas as emissões em reais. Por outro lado, após a primeira emissão em 2005, as emissões em reais em 2006 e 2007 são parcela relevante das emissões totais.

O aumento das reservas internacionais teve papel primordial na redução da vulnerabilidade externa e maior flexibilidade na gestão do passivo externo, mas, por outro lado, teve um custo fiscal, dado pela diferença entre a remuneração dessas reservas e o custo da dívida externa. A elevação das reservas internacionais pode ocorrer por intermédio de compras de divisas no mercado, em que o Banco Central adquire parte das divisas ofertadas por exportadores de bens e serviços, entrada de rendas ou de capitais. A compra dessas divisas pela autoridade monetária tem, em geral, de ser esterilizada em algum grau. Isto decorre dos efeitos expansionistas da moeda sobre a economia, o que não é compatível, por exemplo, com um sistema de metas para a inflação que utilize a taxa de juros de curto prazo como instrumento de política monetária. O custo fiscal aparece pela necessidade de emissão de títulos públicos para enxugar a liquidez gerada pela compra de divisas ou a sua anulação através de um superávit fiscal primário. Estimativas do custo das reservas internacionais brasileiras podem ser encontradas em Cavalcanti e Vonbun (2008). 
Tabela 2 - Emissão de títulos soberanos do Brasil (em US\$ milhões de dólares de 2011)

\begin{tabular}{cccc}
\hline & Total & Em reais & Reais/Total \\
\hline 1995 & 2465 & - & - \\
1996 & 1808 & - & - \\
1997 & 5713 & - & - \\
1998 & 3745 & - & - \\
1999 & 10438 & - & - \\
2000 & 15777 & - & - \\
2001 & 10588 & - & - \\
2002 & 4928 & - & - \\
2003 & 7122 & - & - \\
2004 & 6826 & - & - \\
2005 & 14381 & 1703 & 11,8 \\
2006 & 6079 & 1551 & 25,5 \\
2007 & 3128 & 2016 & 64,4 \\
2008 & 677 & 0,0 & 0,0 \\
2009 & 2682 & 0,0 & 0,0 \\
2010 & 2907 & 676 & 23,3 \\
2011 & 1650 & 0,0 & 0,0 \\
\hline
\end{tabular}

Fonte: Cálculo e elaboração próprios com base em dados do Banco Central do Brasil.

Como as intervenções do Banco Central no mercado cambial são condicionadas pela conjuntura, visando evitar movimentos indesejados na taxa de câmbio (Banco Central do Brasil, 2005, 2008, 2009), a tendência de apreciação da moeda brasileira entre 2003 e 2008, e março de 2009 e julho de 2011 tornou preponderantes as intervenções de compra de divisas nesse período, o que significa efeito monetário expansionista. O trade off existente entre a estabilização cambial, possivelmente obtida através de compras de divisas, e o custo de manutenção das reservas gera um desestímulo às emissões soberanas, uma vez que o nível de reservas internacionais é suficientemente alto para possibilitar eventuais intervenções de venda e funcionar como "seguro" ante instabilidades.

Apesar de não serem necessárias do ponto de vista de acumulação de reservas como o foram em outros períodos, o custo das emissões externas com o objetivo de gerar a referência para papéis privados e obtenção de informações deve compensar o seu custo fiscal na ótica das autoridades brasileiras. O volume das emissões é calibrado para possibilitar a liquidez necessária à formação de taxas no mercado secundário, $\mathrm{o}$ que é chamado pelo Tesouro Nacional de emissões de caráter qualitativo (Silva e Medeiros, 2009).
No caso da emissão de títulos da dívida externa soberana, as reservas podem ser aumentadas sem relação com as operações no sistema financeiro doméstico. No balanço da autoridade monetária um aumento do passivo externo é compensado por um aumento no ativo externo. Entretanto, como o Banco Central ou, mais amplamente, o governo não gera divisas para atender ao serviço da dívida será necessária a aquisição de moeda externa no futuro, o que significa uma troca no tempo do custo fiscal.

A elevação das reservas internacionais brasileiras levou à redução da emissão de títulos da dívida externa soberana. Como não há necessidade de elevação das reservas para pagamentos relacionados à dívida externa, a funcionalidade da emissão de títulos para referência dos mercados passou a ser relevante. Os dados da Tabela 3 mostram que de 2005 a 2010 foram emitidos R \$ 11,3 bilhões, equivalentes a US\$ 5,4 bilhões. Para se ter noção das grandezas envolvidas, estes valores correspondem a $0,5 \%$ da dívida pública mobiliária federal interna em dezembro de 2011, a 1,8\% da dívida externa total e a $2 \%$ da dívida externa registrada. Como a participação da dívida denominada em reais é de $4,8 \%$ do total em setembro de 2011, já é possível notar a importância das emissões soberanas para o mercado de emissões privadas.

Tabela 3 - Emissões brasileiras soberanas em reais

\begin{tabular}{lcccc}
\hline \multicolumn{1}{c}{ Emissão } & Vencimento & Valor em R\$ & Valor em US\$ & Rendimento (\% a.a.) \\
\hline $19 / 09 / 2005$ & $05 / 01 / 2016$ & 3400 & $\mathbf{1 4 7 8 , 8}$ & $\mathbf{1 2 , 7 5}$ \\
$13 / 09 / 2006$ & $05 / 01 / 2022$ & $\mathbf{1 6 0 0}$ & 743,4 & $\mathbf{1 2 , 8 7 5}$ \\
$13 / 10 / 2006$ & $05 / 01 / 2022$ & $\mathbf{6 5 0}$ & 300,7 & $\mathbf{1 2 , 4 6 6}$ \\
$11 / 12 / 2006$ & $05 / 01 / 2022$ & 750 & $346, \mathbf{1}$ & $\mathbf{1 1 , 6 6 3}$ \\
$14 / 02 / 2007$ & $10 / 01 / 2028$ & $\mathbf{1 5 0 0}$ & $7 \mathbf{1 4 , 7}$ & $\mathbf{1 0 , 6 8}$ \\
$27 / 03 / 2007$ & $10 / 01 / 2028$ & 750 & 360,8 & $\mathbf{1 0 , 2 7 9}$ \\
$17 / 05 / 2007$ & $10 / 01 / 2028$ & $\mathbf{7 8 7 , 5}$ & $\mathbf{3 8 9 , 2}$ & $\mathbf{8 , 9 3 8}$ \\
$26 / 06 / 2007$ & $10 / 01 / 2028$ & 750 & 393,5 & $\mathbf{8 , 6 2 6}$ \\
$27 / 10 / 2010$ & $10 / 01 / 2028$ & $\mathbf{1 1 0 0}$ & $\mathbf{6 5 5 , 5}$ & $\mathbf{8 , 8 5}$ \\
\hline
\end{tabular}

Fonte: Secretaria do Tesouro Nacional.

Outro aspecto que é possível verificar a partir dos dados da Tabela 3 é o comportamento dos rendimentos dos títulos emitidos. A primeira emissão, de 2005 com vencimento em 2016, pagou a taxa de $12,75 \%$ ao ano. As emissões de 2006, com vencimento em 2022, pagaram taxas menores a cada emissão. Em comparação com o título de vencimento em 2016, emitido no ano anterior, todas as taxas das emissões de 2006 são menores, mesmo que com vencimento cinco anos à frente. Como prazos mais 
longos significam riscos maiores, a redução da taxa significa a redução desse risco percebido, a redução das taxas esperadas para o período entre os vencimentos (2016 a 2022) ou uma combinação de ambos. Também é interessante observar que, no curto intervalo de três meses entre a primeira e a terceira emissões de 2006, o rendimento pago pelos títulos emitidos tem forte redução de 1,2 ponto percentual, de 12,9\% ao ano para $11,7 \%$ ao ano. Este movimento de redução de custo nas emissões de títulos soberanos em reais ocorre nas emissões de 2007, com vencimento em 2022. Nos quatro meses entre a primeira emissão, em fevereiro, e a quarta, em junho, o rendimento dos títulos reduziu-se em dois pontos percentuais, de $10,7 \%$ ao ano para $8,6 \%$ ao ano. Isto comprova a gestão ativa da dívida quanto ao momento da emissão, já que a decisão de reabertura das emissões ocorria em condições mais favoráveis ao emissor. A emissão de 2010 ocorre com custo levemente superior.

\subsection{CONJUNTURA NA EMISSÃO DE TíTULOS}

Esta análise dos dados de emissões soberanas e da conjuntura em que ocorrem comprova a utilização dos títulos como criadores de benchmark, dado que as emissões ocorrem em momentos favoráveis ao país em termos de custos. Em períodos de maior aversão ao risco nos mercados externos as emissões soberanas não ocorrem. Por exemplo, não ocorreram emissões soberanas no $2^{\circ}$ semestre de 2008 . No caso das emissões em reais elas deixaram de ocorrer em julho de 2007 e voltam somente em outubro de 2010. O final de julho de 2007 é o momento em que a crise dos empréstimos subprime nos Estados Unidos torna-se irreversível, com efeitos em todos os segmentos do mercado financeiro internacional que estouram definitivamente em setembro de 2008. No $2^{\circ}$ semestre de 2010 a inserção do Brasil no mercado financeiro internacional é normal e a emissão de títulos em reais ocorre em um contexto favorável.

O pequeno número de emissões em reais, nove ao longo de sete anos, não permite a utilização de técnicas econométricas para tentar detectar estatisticamente as características distintivas dos momentos em que ocorrem as emissões. Com isto não é possível caracterizar quantitativamente as variáveis que condicionam o gerenciamento da emissão dos títulos pelo governo brasileiro. Como a decisão de emissão é idiossincrática, poderia ser possível detectar características comuns às emissões em termos de variáveis econômicas e financeiras relevantes nos cenários interno e externo, caso a quantidade de emissões fosse maior.

A gestão ativa do governo brasileiro sobre o momento de emitir os títulos em reais pode ser vista através do comportamento das variáveis financeiras relevantes para a contextualização e os custos das emissões. Estas variáveis são mostradas no Gráfico 4 A primeira emissão, em 2005, claramente tem o objetivo de testar a existência de mercado para esse tipo de título. A taxa Selic estava em níveis elevados para controlar a inflação associada à expansão da demanda. As taxas prefixadas mais longas, como a de um ano (DIPRE 360), já estavam em declínio. Também é interessante observar a estabilidade das taxas dos títulos pós-fixados atrelados à inflação, as NTN-B.

O conjunto de emissões ocorridas no segundo semestre de 2006, com vencimento em 2022, e no primeiro semestre de 2007, com vencimento em 2028, ilustram o aproveitamento da melhoria do cenário para a emissão dos títulos. Todas as taxas de juros associadas aos títulos de dívida brasileira estavam em queda. A taxa Selic estava na fase final de um longo ciclo de queda, acompanhada de redução das taxas prefixadas de um ano. A taxa de juros real dos títulos pós-fixados com vencimentos próximos aos dos títulos emitidos no exterior também estava com tendência de redução, atingindo valores que somente seriam praticados novamente em 2010. A série do custo real da dívida pós-fixada mostra a tendência de redução ao longo do tempo, acompanhando a queda estrutural da taxa de juros brasileira. O risco país, medido pelo EMBI+ (EMBIBR), também está em um ciclo de queda nesse período, atingindo no primeiro semestre de 2007 os seus valores mais baixos da série iniciada em 1994. Com relação às variáveis externas, pode-se observar também que a taxa de juros do título de 10 anos do Tesouro dos Estados Unidos (T10Y) não parece ter uma relação clara com as demais variáveis.

\section{Gráfico 4 - Variáveis financeiras}

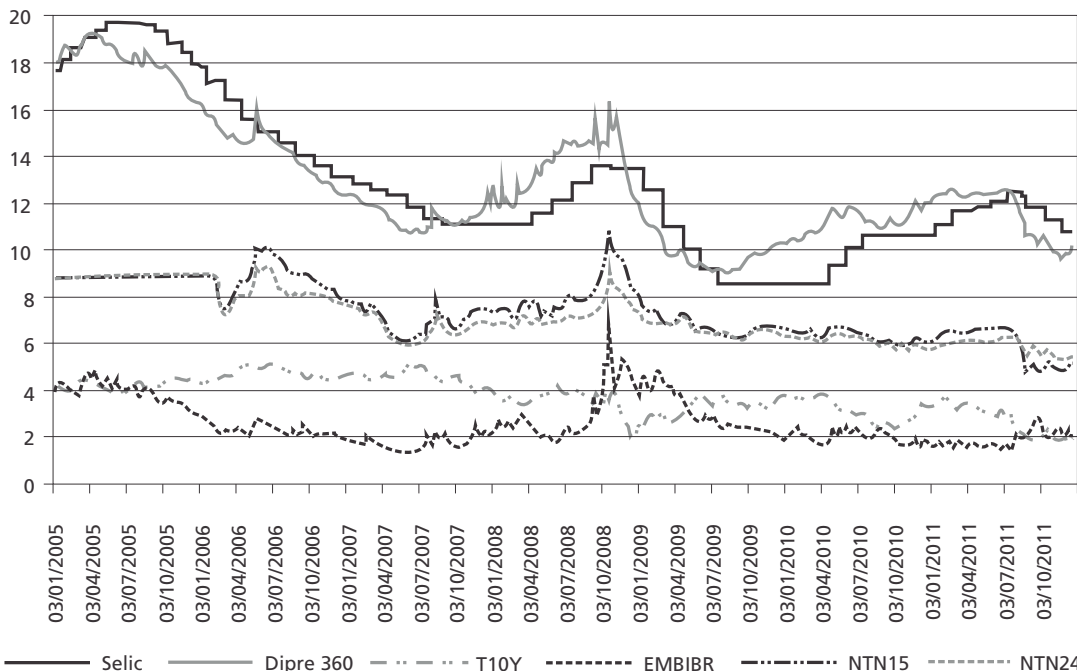

Fonte: Elaboração própria com base em dados do Banco Central do Brasil, Tesouro Nacional, Ipeadata e Federal Reserve de St. Louis. 
A Tabela 4 mostra a correlação entre estas variáveis. Algumas relações fortes entre variáveis domésticas podem ser facilmente explicadas. O rendimento das NTN-B com vencimento em 2015 e 2024 (NTN15 e NTN24) é exposto a riscos similares, diferindo basicamente pela sua maturidade. Com isto, a correlação de 0,95 é plausível, embora o risco de elevações de juros no título mais longo seja maior. O mesmo raciocínio explica a forte correlação de 0,93 entre a taxa Selic e a taxa de juros de um ano. A relação entre a taxa de juros de curtíssimo prazo, através da qual é operacionalizada a política monetária, e a taxa prefixada de um ano é explicada através da estrutura a termo da taxa de juros. O intervalo entre as reuniões do Comitê de Política Monetária (CO$\mathrm{POM})$ que definem a taxa e a suavização de taxas dão persistência no tempo às alterações das taxas de curtíssimo prazo. O efeito das alterações do juro curto sobre as taxas reais, que afetam os títulos com taxas atreladas à inflação, é ilustrado pela elevada correlação entre as taxas Selic e de um ano com a das NTN-B.

Tabela 4 - Correlação entre as variáveis (dados diários, de 2005 a 2011)

\begin{tabular}{lcccccc}
\hline & SELIC & DIPRE360 & T10Y & EMBIBR & NTN15 & NTN24 \\
\hline SELIC & 1 & & & & & \\
DIPRE360 & 0,926 & 1 & & & & \\
T10Y & 0,444 & 0,451 & 1 & & & \\
EMBIBR & 0,572 & 0,546 & $-0,060$ & 1 & & \\
NTN15 & 0,739 & 0,783 & 0,616 & 0,587 & 1 & \\
NTN24 & 0,857 & 0,850 & 0,592 & 0,637 & 0,950 & 1 \\
\hline
\end{tabular}
Fonte: Elaboração própria com base em dados de Banco Central do Brasil, Tesouro Nacional, Ipeadata e Federal Reserve

A taxa de juros do título de 10 anos do Tesouro dos Estados Unidos (T10Y), exógena à economia brasileira, tem correlação baixa com as taxas de juros internas. Estas são determinadas de acordo com a evolução do cenário nacional para a inflação e o produto. $\mathrm{O}$ diferencial entre os rendimentos dos títulos do Tesouro dos Estados Unidos e dos títulos brasileiros emitidos no exterior é influenciado tanto por variáveis internas quanto externas. As expectativas em relação à capacidade de pagamento dos títulos, relacionadas à capacidade fiscal do Estado e à situação das contas externas estão vinculadas à economia do país, embora influenciadas pelo cenário externo. Por outro lado, a interligação entre os mercados faz com que haja movimentos comuns a ativos de diferentes países (Forbes e Rigobon, 2002; Baig e Goldfajn, 1999). Como os riscos dos títulos brasileiros no exterior não são os mesmos dos títulos domésticos, por não estarem sujeitos a risco cambial no caso de denominados em moeda estrangeira e não terem risco de conversibilidade, a relação entre as taxas de juros internas e o risco país não é tão forte. A definição exógena dos juros dos Estados Unidos é confirmada pela correlação baixa com os juros brasileiros e, especialmente, pela correlação praticamente nula com o risco país, o que explica a utilização dos títulos dos Estados Unidos como investimento de baixo risco.

O objetivo de criar um benchmark com os títulos da dívida soberana significa dar importância ao mercado secundário desses títulos, como medida de risco sistemático e também para revelar as expectativas do mercado em relação à evolução da economia do país. Para que os títulos negociados no mercado secundário desempenhem este papel, entretanto, é necessário que os volumes negociados sejam relevantes e haja liquidez para os títulos. Caso isto não ocorra, pequenas alterações nas quantidades ofertadas ou demandadas gerarão grandes oscilações nos preços (e rendimentos) dos títulos, sem necessariamente ter relação com percepções sobre ou com os próprios fundamentos subjacentes aos títulos. A importância da liquidez dos títulos pode ser ilustrada pelo fato de os títulos participantes do EMBI+ apurado pelo JP Morgan terem de atender a certos critérios de liquidez e volume de títulos em circulação.

Isto é considerado no caso das emissões brasileiras em reais, porque há preocupação em não diluir os vencimentos, que diminuiria as possibilidades de negociação de cada título. Um trade off da concentração de vencimentos é o risco decorrente da maior exposição à conjuntura no momento do vencimento. Os vencimentos dos títulos emitidos em reais são somente três. A emissão de 2005 vence em 2016, as três emissões de 2006 vencem em 2022, e as quatro emissões de 2007 e a de 2010 vencem em 2028. A reabertura das emissões para determinado vencimento evita a diluição e permite maior negociabilidade dos títulos.

\subsection{EMISSÕES EXTERNAS E DÍVIDA PÚBLICA INTERNA}

Como existe pelo menos algum grau de substituição entre títulos internos e externos, a emissão de títulos em reais no exterior, sem risco cambial para o emissor local, pode influenciar o comportamento do mercado de títulos emitidos no mercado nacional Dos títulos emitidos no mercado interno, os mais similares aos emitidos no mercado externo em reais são as NTN-F. As NTN-C são indexadas à inflação medida pelo IGP-M e não são emitidas atualmente. As NTN-B, atreladas à inflação medida pelo IPCA, também são pós-fixadas. As LFT têm seu rendimento atrelado à taxa Selic. A diferença entre os títulos prefixados LTN e NTN-F é a existência de cupom semestral nas NTN-F. Como os títulos emitidos no exterior em reais também têm cupom semestral são comparáveis às NTN-F. 
O estoque de títulos no mercado interno em comparação ao volume de títulos em reais emitidos no exterior mostra que não ocorreu uma migração relevante dos negócios com títulos da dívida pública brasileira para o exterior. O grau de integração ou segmentação dos mercados interno e externo de dívida pública é um tema a ser estudado.

O Gráfico 5 mostra o estoque de títulos emitidos pelo Tesouro Nacional no mercado doméstico em poder do público. O volume de NTN-F começa a aumentar, significativamente, a partir do segundo semestre de 2006 e já é parte relevante da composição da dívida pública brasileira.

\section{Gráfico 5 - Estoque de títulos emitidos pelo Tesouro Nacional em poder do público} (em R\$ bilhões)

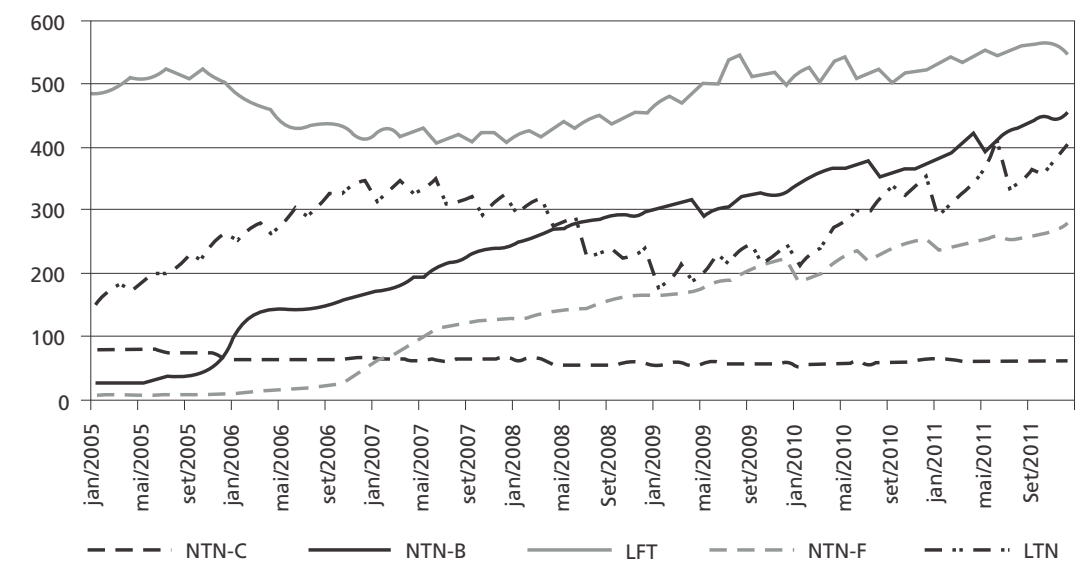

Fonte: Elaboração própria com base em dados de Banco Central do Brasil, Notas Econômico-Financeiras para a Imprensa - Mercado Aberto.

O prazo médio desses títulos, mostrado no Gráfico 6, é consistente com o perfil de risco dos títulos. Os títulos prefixados, mais expostos ao risco de mercado, têm prazos mais curtos. As LFT poderiam ter prazos mais longos, mas a gestão da dívida pública brasileira está procurando reduzir o seu peso na composição da dívida, porque o fato de ter rendimento atrelado ao juro de curtíssimo prazo faz com que a presença desses títulos reduza a potência da política monetária (Barbosa, 2006). O prazo médio das NTN-F oscilou entre 22,8 meses no final de 2011 e 41 meses em outubro de 2006. Estes prazos são consideravelmente menores que os dos títulos brasileiros em reais emitidos no exterior. Isto mostra que ainda não ocorreu convergência de prazos entre os mercados interno e externo dos títulos com características similares. Ao longo dos anos, entretanto, o Tesouro Nacional está conseguindo colocar NTN-F de prazos mais longos.
No início de 2005 eram vendidas somente NTN-F com vencimento em 2008. Como comparação, em dezembro de 2011 também eram vendidos títulos com vencimento em 2021.

\section{Gráfico 6 - Prazo médio do estoque de títulos emitidos pelo Tesouro Nacional no} mercado doméstico (em meses)

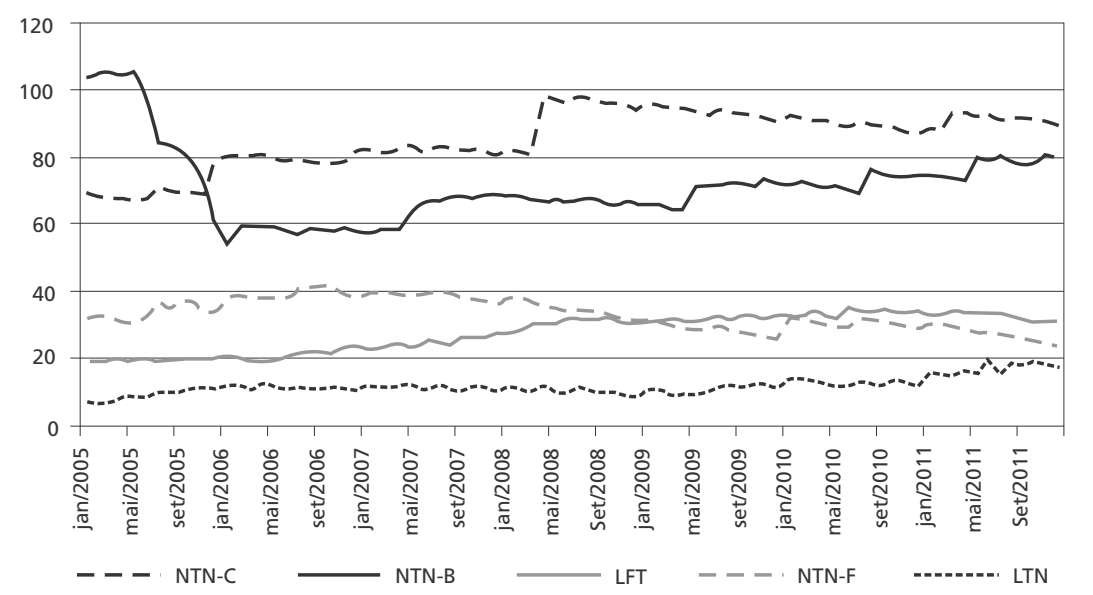
Fonte: Elaboração própria com base em dados de Banco Central do Brasil, Notas Econômico-Financeiras para a Im-
prensa - Mercado Aberto.

Se há um mercado externo para os títulos de prazos mais longos em moeda local isto significa algum grau de previsibilidade do seu retorno. Neste sentido é interessante observar que o prazo dos títulos prefixados emitidos em reais é maior no exterior do que no mercado doméstico, embora os volumes sejam muito superiores no mercado interno. Há duas explicações possíveis para isto. Por um lado, os investidores estrangeiros podem ter maior acesso a conhecimento e talento do que os investidores domésticos e, com isto, estarem dispostos a comprar títulos mais longos em comparação a investidores locais. Por outro, os investidores locais poderiam ter mais acesso a informação do que os investidores estrangeiros. Em termos empíricos esta questão não está resolvida (Choe, Kho e Stulz, 2005). Caso os investidores nacionais ou estrangeiros tivessem vantagem informacional, sistematicamente, isto significaria que os mercados interno e externo da dívida pública brasileira se tornariam segmentados, e as possibilidades de arbitragem entre eles não poderiam ser exploradas, o que é difícil de aceitar considerando o grau de sofisticação e de abertura do mercado financeiro brasileiro.

A segunda possibilidade é que os investidores estrangeiros utilizem os títulos brasileiros como uma opção. O diferencial de juros entre os títulos brasileiros e os de 
menor risco, como os do Tesouro dos Estados Unidos, por exemplo, é muito elevado. Como a taxa de câmbio real não pode se apreciar ou depreciar, indefinidamente, a compra de títulos brasileiros de longo prazo pode gerar retornos muito elevados, caso a evolução do cenário macroeconômico brasileiro seja favorável. Caso haja perdas, estas não causarão danos exagerados às carteiras porque os volumes envolvidos não são muito elevados. Este poderia ser considerado um investimento especulativo. Por outro lado, caso haja uma tendência à convergência entre as taxas internacionais e brasileira, as expectativas de estabilidade macroeconômica no Brasil gerarão elevados retornos, mesmo que possam ser considerados especulativos no curto prazo.

A estabilidade e previsibilidade da inflação e, mais amplamente, de toda a economia têm papel relevante em possibilitar a convergência das taxas de juros longas do Brasil para taxas internacionais e a consequente redução do custo da dívida pública e do custo de capital para as empresas. Isto mostra a importância da estabilidade macroeconômica para o mercado de títulos.

\section{IMPLICAÇÕES PARA A GESTÃO DA DÍVIDA PÚBLICA E O MERCADO FINANCEIRO}

A discussão anterior mostra a relevância da estabilidade macroeconômica para a estratégia de obtenção de financiamento externo. Caso o país adote em sua estratégia de crescimento a utilização de poupança externa, ou seja, incorrer em déficits em transações correntes, a diversificação de fontes de origem de recursos externos passa a ser importante. Isto pode se referir tanto para o tomador de recursos público ou privado, quanto à destinação dos recursos para investimento direto externo, investimento externo em carteira ou dívida contratual.

No caso do investimento em carteira, a possibilidade de diversificação entre títulos representativos de propriedade (ações) ou de dívida já é uma das possibilidades de diversificação. Dentre os títulos de dívida, a composição em termos de moeda de denominação pode reduzir a variabilidade da dívida decorrente de movimentos na taxa de câmbio. A emissão de títulos em moeda local elimina o risco cambial para os emissores nacionais, especialmente o governo, que não tem a possibilidade de obter receita relevante em moeda estrangeira fora a remuneração das reservas internacionais. Estas emissões em moeda local podem servir como benchmark para emissões corporativas, servindo para reduzir o risco sistemático desses títulos, associado à economia do país. Com isso a emissão de títulos públicos pode ter importância para facilitar a emissão de títulos privados, assegurando esta possibilidade de diversificação de origem de recursos.

A emissão dos títulos de dívida externa serve, portanto, para revelar e obter informação sobre a economia do país e a percepção dos agentes de mercado sobre ela. Como a emissão de títulos prefixados de prazos longos significa alguma previsibilidade nos retornos, associados ao risco de inflação, as emissões podem sinalizar o comprometimento do governo com a estabilidade de preços e das variáveis que a condicionam.

Inversamente, a existência de mercado para os títulos locais longos no exterior pode servir para estimular o alongamento dos prazos no mercado interno, o que tem uma relação importante com o funding para operações com títulos e crédito de longo prazo. Isto remete, novamente, à estabilidade das variáveis macroeconômicas e suas expectativas para possibilitar as estimativas de risco e retorno.

Caso as emissões prefixadas em reais no exterior tenham influência sobre a ampliação do volume e prazo das emissões domésticas, um dos efeitos será a melhoria dos mecanismos de transmissão da política monetária. A inter-relação entre a operação da política monetária com a política fiscal também influenciará a trajetória das taxas reais de juros.

\section{CONCLUSÃO}

As emissões de títulos da dívida pública externa denominados em reais, a partir de 2005, não foram utilizadas como fonte de financiamento externo. A acumulação de reservas internacionais, a mudança no perfil da dívida externa e a entrada de capitais para investimento externo direto e de carteira permitiram ao governo brasileiro uma relativa flexibilidade em sua relação com o sistema financeiro internacional.

A importância dessas emissões está em criar uma referência para a emissão de títulos corporativos, porque os títulos soberanos reduzem o risco sistemático associado à economia do país. Uma vantagem da emissão em reais no exterior é a ausência do risco de câmbio para o devedor doméstico, o que também pode ser utilizado como operação de hedge por parte de investidores externos. Por outro lado, o fato de serem negociados no mercado externo significa que não estão sujeitas ao risco de conversibilidade, associado a dificuldades de o país efetuar pagamentos no exterior ou a controles de capitais.

As emissões brasileiras ocorreram com prazos mais longos que os títulos comparáveis emitidos no mercado interno. A interligação entre o mercado financeiro local e o internacional pode gerar um aumento dos prazos da dívida doméstica, com efeitos sobre o funding de operações no mercado financeiro. Desta forma, as emissões privadas poderiam ocorrer a custos mais baixos, reduzindo o custo de capital para as empresas.

O fato de o país não depender dos recursos das captações externas para fazer frente ao serviço de sua dívida permitiu a escolha dos momentos favoráveis à emissão 
em termos de custos. A primeira emissão em 2005, com títulos vencendo em 2016, não foi reaberta. As emissões posteriores foram reabertas com a obtenção de taxas menores, acompanhando a conjuntura favorável. Com as novas emissões o prazo obtido foi sendo ampliado para vencimentos em 2022 e 2028.

Um aspecto importante da emissão de títulos prefixados em reais no exterior é a sua sinalização de que a política econômica está comprometida com o controle dos preços, uma vez que taxas de inflação muito elevadas eliminariam o valor dos títulos. Neste sentido as emissões no exterior podem influenciar também emissões internas. As emissões externas em reais podem influenciar a composição da dívida doméstica, relacionada, por sua vez, com a transmissão da política monetária e a trajetória dos juros. Isto se relaciona, também, com a operação do sistema financeiro, por sua ligação com os prazos dos títulos corporativos e do funding para as operações de crédito.

Um aspecto importante a ser estudado é a relação entre os movimentos do retorno dos títulos em reais emitidos no mercado interno e no exterior. Isto possibilitaria verificar a ocorrência de arbitragem entre esses mercados ou a antecipação de movimentos em algum deles, bem como quantificar o risco de conversibilidade associado aos títulos negociados no mercado doméstico, já que as demais características dos títulos são muito próximas, à exceção do local de negociação.

\section{REFERÊNCIAS}

BAIG, T.; GOLDFAJN, I. Financial market contagion in the Asian crisis. IMF Staff Papers, v. 46, n. 2, 1999.

BANCO CENTRAL DO BRASIL. Boletim do Banco Central do Brasil. Relatório Anual, v. 45, 2009.

BANCO CENTRAL DO BRASIL. Boletim do Banco Central do Brasil. Relatório Anual, v. 44, 2008.

BANCO CENTRAL DO BRASIL. Boletim do Banco Central do Brasil. RelatórioAnual, v. 41, 2005.

BANK FOR INTERNATIONAL SETTLEMENTS (BIS). BIS Quarterly Review, Dec. 2011.

BARBOSA, F. H. The contagion effect of public debt on monetary policy: the Brazilian experience. Revista de Economia Política, v. 26, n. 2, p. 231-238, 2006.

BEKAERT, G.; HARVEY, C. R. Foreign speculators and emerging equity markets. Journal of Finance, v. 40 , n. 2, p. 565-613, 2000

BURGER, J. D.; WARNOCK, F. E. Diversification, original sin, and international bond portfolios. International Finance Discussion Papers, Board of Governors of the Federal Reserve System, n. 755, 2003.
CAVALCANTI, M. A. F. H.; VONBUN, C. Reservas Internacionais ótimas para o Brasil: uma análise simples de custo-benefício para o período 1999-2007. Economia Aplicada, v. 12, n. 3, p. 463-498, 2008.

CERQUEIRA, C. A. Dívida externa brasileira. 2 ed. Brasília: Banco Central do Brasil, 2003.

CHOE, H; KHO, B-C.; STULZ, R. M. Do domestic investors have an edge? The trading experience of foreign investors in Korea. Review of Financial Studies, v. 18, n. 3, p. 795-829, 2005.

CLAESSENS, S. The optimal currency composition of external debt: theory and applications to Mexico and Brazil. The World Bank Economic Review, v. 6, n. 3, p. 503-528, 1992.

CLARK, J.; BERKO, E. Foreign investment fluctuations and emerging market returns: the case of Mexico. Staff Report, Federal Reserve Bank of New York, n. 24, 1997.

DE BONDT, W. F. M.; THALER, R. H. Do security analysts overreact? American Economic Review, v. 80, n. 2, p. 52-57, 1990.

DITTMAR, R.F.; YUAN, K. Do sovereign bonds benefit corporate bonds in emerging markets? Review of Financial Studies, v. 21, n. 5, p. 1983-2014, 2008.

DOOLEY, M. P. Debt management and crisis in developing countries. Journal of Development Economics, v. 63, p. 45-58, 2000.

EDWARDS, S. Sequencing reforms, financial globalization, and macroeconomic vulnerability. NBER Working Paper, n. 14384, 2008.

ERRUNZA, V. Foreign portfolio equity investments, financial liberalization, and economic development. Review of International Economics, v. 9, n. 4, p. 703-726, 2001.

FABELLA, R.; MADHUR, S. Bond market development in East Asia: issues and challenges. European Report on Development Working Paper Series, European University Institute, n. 35, 2003.

FORBES, K. J.; RIGOBON, R. No contagion, only interdependence: measuring stock market comovements. Journal of Finance, v. 57, n. 5, p. 2223-2261, 2002.

GRIFFITH-JONES, S.; OCAMPO, J. A. The financial crisis and its impact on developing countries. Working Paper, International Policy Centre for Inclusive Growth, n. 53, 2009.

HOTI, S. An empirical evaluation of international capital flows for developing countries. Math ematics and Computers in Simulation, v. 64, p. 143-160, 2004.

HUSSEIN, K.; MELLO JR., L. R. Is foreign debt portfolio management efficient in emerging economies? Journal of Development Economics, v. 66, p. 317-335, 2001.

JEANNEAU, S.; TOVAR, C.E. Latin America's local currency bond markets: an overview. BIS Papers, n. 36, 2008.

SALGADO, R. B. I. A reação do mercado de títulos corporativos da dívida externa a emissões soberanas brasileiras. São Paulo: ANBID, 2009.

SILVA, A. D. B. M.; MEDEIROS, O. L. Conceitos e estatísticas da dívida pública. In: SILVA, A. C.; CARVALHO, L. O.; MEDEIROS, O. L. (Orgs.) Dívida pública: a experiência brasileira. Brasília: Secretaria do Tesouro Nacional, Banco Mundial, 2009, p. 101-128.

YUAN, K. The liquidity service of benchmark securities. Journal of the European Economic Association, v. 3, n. 5, p. 1156-1180, 2005 